\title{
Impact and natural history of postprocedural aortic regurgitation on early and midterm mortality following transcatheter aortic valve implantation in high-risk patients with severe aortic stenosis
}

Ielasi, Alfonso ; Latib, Azeem ; Sacco, Francesco Maria ; Costopoulos, Charis ; Figini, Filippo ; Grimaldi, Antonio ; Naim, Charbel ; Maisano, Francesco ; Chieffo, Alaide ; Montorfano, Matteo ; Alfieri, Ottavio ; Colombo, Antonio

\begin{abstract}
BACKGROUND: Post-procedural aortic regurgitation (AR) negatively impacts the prognosis after trans-catheter aortic valve implantation. However, data evaluating the impact of different postprocedural AR grades (particularly mild) on clinical outcomes are still important. AIM AND METHODS: A retrospective cohort analysis was performed on all consecutive patients with severe aortic stenosis who underwent trans-catheter aortic valve implantation between July 2008 and August 2011 in a single Institution. Aim of the study was to evaluate the impact of different post-procedural AR grades on early and mid-term clinical outcomes. RESULTS: 322 consecutive patients were evaluated. At postprocedural echocardiographic evaluation: 105 (32.6\%) patients had no AR, 204 (63.4\%) mild AR and 13 (4\%) moderate/severe AR. In-hospital mortality was higher in patients with moderate/severe AR than in those with absent or mild AR $(38.5 \%$ vs. $2.6 \%, \mathrm{P}<0.001)$. At a median clinical follow-up of 342 days [interquartile range $93-485$ ] cardiovascular mortality was $2.9 \%$ in patients without AR; $13.2 \%$ in the mild AR group $(\mathrm{P}=0.004$ vs. absent $\mathrm{AR})$ and $46.2 \%$ in the moderate/severe $\mathrm{AR}$ group $(\mathrm{P}<0.001$ vs. mild or absent AR). On multivariable analysis, post-procedural AR (hazard ratio $=2.65$ absent vs. present any grade, $95 \%$ confidence interval $=1.11-6.29 ; \mathrm{P}=0.027)$ was an independent predictor of mid-term mortality. CONCLUSIONS: The impact of post-procedural AR on outcomes after trans-catheter aortic valve implantation is proportional with its grade even in case of mild post-procedural AR compared to absent. This study confirms that every effort should be made to reduce the grade of post-procedural AR after trans-catheter aortic valve implantation with current devices.
\end{abstract}

DOI: https://doi.org/10.2459/JCM.0000000000000249

Posted at the Zurich Open Repository and Archive, University of Zurich

ZORA URL: https://doi.org/10.5167/uzh-120092

Journal Article

Published Version

Originally published at:

Ielasi, Alfonso; Latib, Azeem; Sacco, Francesco Maria; Costopoulos, Charis; Figini, Filippo; Grimaldi, Antonio; Naim, Charbel; Maisano, Francesco; Chieffo, Alaide; Montorfano, Matteo; Alfieri, Ottavio; Colombo, Antonio (2015). Impact and natural history of postprocedural aortic regurgitation on early and midterm mortality following transcatheter aortic valve implantation in high-risk patients with severe aortic stenosis. Journal of Cardiovascular Medicine, 16(4):286-295.

DOI: https://doi.org/10.2459/JCM.0000000000000249 


\title{
Impact and natural history of postprocedural aortic regurgitation on early and midterm mortality following transcatheter aortic valve implantation in high-risk patients with severe aortic stenosis
}

\author{
Alfonso lelasi ${ }^{a_{* *}}$, Azeem Latib $^{a, b_{*}}$, Francesco Maria Sacco ${ }^{a}$, \\ Charis Costopoulos ${ }^{\mathrm{a}, \mathrm{b}}$, Filippo Figini ${ }^{\mathrm{a}, \mathrm{b}}$, Antonio Grimaldi ${ }^{\mathrm{c}}$, \\ Charbel Naim ${ }^{a}$, Francesco Maisanoc ${ }^{c}$, Alaide Chieffo ${ }^{a}$, \\ Matteo Montorfano ${ }^{a}$, Ottavio Alfieri ${ }^{c}$ and Antonio Colombo ${ }^{a, b}$
}

\begin{abstract}
Background Post-procedural aortic regurgitation (AR) negatively impacts the prognosis after trans-catheter aortic valve implantation. However, data evaluating the impact of different post-procedural AR grades (particularly mild) on clinical outcomes are still important.
\end{abstract}

\begin{abstract}
Aim and Methods A retrospective cohort analysis was performed on all consecutive patients with severe aortic stenosis who underwent trans-catheter aortic valve implantation between July 2008 and August 2011 in a single Institution. Aim of the study was to evaluate the impact of different post-procedural AR grades on early and mid-term clinical outcomes.
\end{abstract}

Results 322 consecutive patients were evaluated. At postprocedural echocardiographic evaluation: 105 (32.6\%) patients had no AR, $204(63.4 \%)$ mild AR and $13(4 \%)$ moderate/severe AR. In-hospital mortality was higher in patients with moderate/severe AR than in those with absent or mild AR $(38.5 \%$ vs. $2.6 \%, P<0.001)$. At a median clinical follow-up of 342 days [interquartile range 93-485] cardiovascular mortality was $2.9 \%$ in patients without AR; $13.2 \%$ in the mild AR group ( $P=0.004$ vs. absent $A R)$ and $46.2 \%$ in the moderate/severe AR group ( $P<0.001$ vs. mild

\section{Introduction}

Transcatheter aortic valve implantation (TAVI) is an effective and worldwide practiced treatment option for high-risk surgical patients with severe aortic stenosis. ${ }^{1,2}$

Although outcomes following TAVI have improved through developments in technology and increasing clinical experience, postprocedural aortic regurgitation remains relatively common and an important issue as it has been identified as an independent predictor of mortality. ${ }^{3-5}$ Incongruence between device size and aortic annulus dimensions, ${ }^{6,7}$ extensive calcification of the aortic valve ${ }^{8-10}$ and prosthesis malposition ${ }^{11-13}$ are considered the main causes of this phenomenon. Trivial

\footnotetext{
* Dr Alfonso lelasi and Dr Azeem Latib contributed equally to the article and are joint first authors.
}

or absent AR). On multivariable analysis, post-procedural AR (hazard ratio $=2.65$ absent vs. present any grade, $95 \%$ confidence interval $=1.11-6.29 ; P=0.027$ ) was an independent predictor of mid-term mortality.

Conclusions The impact of post-procedural AR on outcomes after trans-catheter aortic valve implantation is proportional with its grade even in case of mild postprocedural AR compared to absent. This study confirms that every effort should be made to reduce the grade of post-procedural AR after trans-catheter aortic valve implantation with current devices.

J Cardiovasc Med 2015, 16:286-295

Keywords: aortic regurgitation, aortic stenosis, transcatheter aortic valve implantation

${ }^{\mathrm{a}}$ Interventional Cardiology Unit, San Raffaele Scientific Institute, ${ }^{\mathrm{b}}$ Interventional Cardiology Unit, EMO-GVM Centro Cuore Columbus and 'Division of Cardiac Surgery, San Raffaele Scientific Institute, Milan, Italy

Correspondence to Azeem Latib, MD, EMO-GVM Centro Cuore Columbus 48 Via M. Buonarroti, 20145 Milan, Italy

Tel: +39 024819 2920; fax: +39 024819 3433; e-mail: alatib@gmail.com

Received 7 July 2014 Revised 4 November 2014 Accepted 10 November 2014

or mild postprocedural aortic regurgitation is actually frequent, ${ }^{6,14-16}$ whereas moderate-to-severe is relatively rare, but it may be associated with increased mortality between 30 days and 1 year. ${ }^{3}$

In the present study, we sought to evaluate the natural history and the impact of different postprocedural aortic regurgitation grades on early and midterm clinical outcomes in patients treated with either the self-expanding CoreValve (Medtronic Inc., Minneapolis, Minnesota, USA) or balloon-expandable Edwards SAPIEN (ESVEdwards Lifesciences, Irvine, California, USA) aortic valve bioprosthesis.

\section{Methods}

A retrospective cohort analysis was performed on 344 consecutive patients with symptomatic severe aortic 
stenosis who underwent TAVI between July 2008 and August 2011 at the San Raffaele Scientific Institute, Milan, Italy. Patients undergoing TAVI for pure aortic regurgitation or valve-in-valve procedures were excluded. All patients referred for consideration of TAVI underwent a systematic assessment including transthoracic echocardiography (TTE), coronary angiography, aortography and iliofemoral angiography, computed tomography scan of the heart, aorta and peripheral vasculature, pulmonary function testing, carotid artery ultrasonography and multidisciplinary evaluation by both a cardiac surgeon and an interventional cardiologist. Informed consent was obtained from each patient, and the study protocol conforms to the ethical guidelines of the 1975 Declaration of Helsinki as reflected in 'a-priori' approval by the institution's human research committee. Prespecified clinical and laboratory data were prospectively collected for all patients on admission, immediately after TAVI and during midterm follow-up. All patients were followed up prospectively, and data on major clinical events and complications during and after TAVI were obtained from hospital documentation, whereas data on events occurring after discharge were derived from follow-up visits or by contacting patients by phone.

TTE or transesophageal echocardiography (TEE) with evaluation of the aortic annulus diameter, aortic mean gradient, aortic peak gradient and aortic valve area (AVA) was performed at admission (preprocedure), discharge and at 30-day, 6-month, 1-year and more than 1-year follow-up visits by the same operator who performed the prior examination.

\section{Procedural details}

Procedural details have already been described elsewhere. ${ }^{17}$ In order to assess the grade of postprocedural aortic regurgitation, an angiogram immediately after transcatheter heart valve (THV) implantation (and approximately $10 \mathrm{~min}$ after CoreValve implantation in case of moderate or severe postprocedural aortic regurgitation) and an intraprocedural TTE or TEE with an established integrative approach for quantitative and semiquantitative grading according to guidelines were performed in all the patients. ${ }^{18}$ In the case of discrepancy between aortography and echocardiography, we always accepted the worst result as our evaluation of the aortic regurgitation grade. In case of moderate-to-severe aortic regurgitation, any countermeasure adopted (i.e. postdilatation, snaring or valve-in-valve implantation) was left to the discretion of the operator.

\section{Aortic regurgitation definition}

The quantitative and semiquantitative hemodynamic assessment of aortic regurgitation severity was performed with Doppler echocardiography and aortography as per guidelines. ${ }^{18-20}$ Aortic regurgitation grading was based on color Doppler imaging through the assessment of the height and width of the regurgitant jet. Short-axis and long-axis TTE views were used to assess the severity of the aortic regurgitation (absent, mild and moderate/ severe). According to the Valve Academic Research Consortium (VARC), ${ }^{21}$ aortic regurgitation was graded as being absent, mild, moderate or severe.

\section{Endpoint definitions}

The primary outcomes evaluated in the present study were all-cause and cardiovascular mortality at follow-up. All the procedural and clinical outcomes were adjudicated internally with the VARC definitions. ${ }^{21}$

\section{Statistical analysis}

Continuous variables were expressed as mean \pm standard deviation, and qualitative variables as numbers and percentages. Comparisons of clinical, echocardiographic, angiographic or procedure-related characteristics of patients, according to presence of postdilatation and different grades of aortic regurgitation, were performed with either the Student's $t$-test (continuous variables) or chi-square statistic (categorical) as appropriate. A Bonferroni test was used to correct for repeated testing when three groups were analyzed. Exploratory multivariable analysis by Cox regression was performed to evaluate the predictors of midterm mortality following TAVI. The variables entered into the initial multivariable model included body mass index (BMI), Society of Thoracic Surgeons (STS) score, left ventricular ejection fraction (LVEF), postprocedural aortic regurgitation, renal failure, logistic EuroSCORE, angina and peripheral vascular disease. Our multivariable model testing used the purposeful selection of covariates strategy as proposed by Hosmer and Lemeshow, and thus our final model was obtained. Survival analyses were performed by KaplanMeier analysis. All analyses were conducted using SPSS software, version 18.0, and all reported $P$-values are twosided. $P$-values $<0.05$ were regarded as statistically significant.

\section{Results}

Between July 2008 and August 2011, a total of 344 patients underwent a TAVI procedure. Among these, 22 patients [16 patients treated for bioprosthetic valve degeneration ('valve-in-valve') and 6 patients for 'isolated' severe aortic regurgitation] were excluded from the final analysis. Thus, a total of 322 patients constituted the cohort of the present study. Baseline clinical, echocardiographic and angiographic characteristics were compared according to the grade of postprocedural aortic regurgitation, which was defined as absent, mild and moderate/severe (Tables 1 and 2). Overall mean patient age was $79.6 \pm 7$ years. New York Heart Association class III/IV was present in $214(66.9 \%)$ patients, whereas 46 $(14.3 \%)$ had a severely reduced $(<40 \%)$ LVEF. Concomitant coronary artery disease was present in $140(44.3 \%)$ patients, and $71(22 \%)$ patients underwent previous 
coronary artery bypass graft. Mean logistic EuroSCORE was $24.0 \pm 16.9 \%$, whereas mean STS score was $9.5 \pm 9.3$. Mean AVA was $0.76 \pm 0.5 \mathrm{~cm}^{2}$. Mean aortic annulus diameter was $22.9 \pm 3.1,23.1 \pm 4.1$ and $22.6 \pm 3.0 \mathrm{~mm}$ at computed tomography scan, TEE and TTE evaluation, respectively. At baseline, 247 (78.3\%) patients were free from aortic regurgitation. Immediately after TAVI, aortic regurgitation was classified as absent in $105(32.6 \%)$ patients, mild in $204(63.4 \%)$ patients and moderate-tosevere in $13(4 \%)$ patients. No significant differences were noted among patients grouped according to postprocedural aortic regurgitation grade (absent, mild and moderate/severe) with regard to baseline clinical characteristics with the exception of AVA (aortic regurgitation absent: $0.8 \pm 0.22 \mathrm{~cm}^{2}$; mild aortic regurgitation: $0.69 \pm 0.21 \mathrm{~cm}^{2}$; moderate/severe aortic regurgitation: $\left.0.65 \pm 0.13 \mathrm{~cm}^{2} ; P=0.003\right)$ and left ventricular enddiastolic diameter (aortic regurgitation absent: $50.5 \pm 6.3 \mathrm{~mm}$; mild aortic regurgitation: $52.9 \pm 7.9 \mathrm{~mm}$; moderate/severe aortic regurgitation: $56.5 \pm 9.5 \mathrm{~mm}$; $P=0.035$ ), which were, respectively, smaller and larger in patients with moderate/severe postprocedural aortic regurgitation.

Procedural characteristics are shown in Table 3. Of the 322 TAVI procedures, $261(81.1 \%)$ were performed transfemorally, $34(10.6 \%)$ through a transaxillary access, 24 $(7.4 \%)$ transapically and $3(0.9 \%)$ through the direct aortic route. The CoreValve was implanted in 128 (39.8\%) patients whereas the Edwards SAPIEN or SAPIEN XT was implanted in $194(60.2 \%)$ patients. Procedural success was achieved in $96 \%$ of patients. The mean transaortic pressure gradient decreased from $53.3 \pm 15.0 \mathrm{mmHg}$ (preprocedure) to $9.8 \pm 4.7 \mathrm{mmHg}$ (postprocedure, $P<0.001)$. THV postdilatation was performed in $61(18.9 \%)$ patients: $14(7.2 \%)$ with the
Edwards SAPIEN and $47(36.7 \%)$ with the CoreValve $(P<0.0001)$.

\section{In-hospital mortality}

In-hospital death occurred in $13(4.0 \%)$ patients. Causes of in-hospital death are shown in Table 4. Death rates were significantly higher in patients with moderate/ severe postprocedural aortic regurgitation than in those with absent or mild aortic regurgitation (38.5 vs. $2.6 \%$, $P<0.001)$. There was no significant difference between patients with absent aortic regurgitation and those with mild aortic regurgitation ( 1 vs. $3.4 \%, P=0.19$ ); however, an increase in hospital death was seen in patients with at least moderate aortic regurgitation (Fig. 1).

\section{Follow-up mortality}

Thirty-day mortality occurred in 14 (4.3\%) patients, with only 1 occurring after discharge, which was attributed to sudden death. This was significantly higher in patients with moderate/severe postprocedural aortic regurgitation than in those with absent or mild aortic regurgitation (38.5 vs. $2.9 \%, P<0.001)$.

At a median clinical follow-up of 342 days (interquartile range 93-485), all-cause mortality occurred in 57 (17.7\%) patients. Figure 1 shows the distribution of cardiovascular and all-cause mortality according to postprocedural aortic regurgitation grade. Table 5 summarizes the causes of death during follow-up. All-cause death occurred in 10 (9.5\%) patients without postprocedural aortic regurgitation, in $40(19.6 \%)$ patients with mild postprocedural aortic regurgitation ( $P=0.023$ vs. no aortic regurgitation) and in $7(53.8 \%)$ patients with moderate/severe postprocedural aortic regurgitation $(P<0.004$ vs. mild aortic regurgitation). Overall cardiovascular mortality occurred in $36(11.2 \%)$ patients: $3(2.9 \%)$ in patients without

Table 1 Baseline clinical characteristics according to postprocedural aortic regurgitation grade

\begin{tabular}{|c|c|c|c|c|c|}
\hline & $\begin{array}{c}\text { Overall } \\
(n=322)\end{array}$ & $\begin{array}{l}\text { No aortic } \\
\text { regurgitation }(n=105)\end{array}$ & $\begin{array}{c}\text { Mild aortic } \\
\text { regurgitation }(n=204)\end{array}$ & $\begin{array}{l}\text { Moderate/severe aortic } \\
\text { regurgitation }(n=13)\end{array}$ & $P$-value \\
\hline Age (years) & $79.6 \pm 7$ & $79.97 \pm 6.8$ & $79.39 \pm 7.14$ & $79.76 \pm 7.66$ & 0.78 \\
\hline Male sex & $165(51.2 \%)$ & $48(45.7 \%)$ & $111(54.4 \%)$ & $6(46.2 \%)$ & 0.32 \\
\hline BMI $\left(\mathrm{kg} / \mathrm{m}^{2}\right)$ & $26.2 \pm 4.6$ & $26.9 \pm 5.1$ & $25.9 \pm 4.2$ & $25.9 \pm 4.3$ & 0.16 \\
\hline Hypertension & $243(75.5 \%)$ & $82(78.1 \%)$ & $153(75.0 \%)$ & $8(61.5 \%)$ & 0.41 \\
\hline Hyperlipidemia & $194(60.2 \%)$ & $68(64.8 \%)$ & $118(57.8 \%)$ & $8(61.5 \%)$ & 0.49 \\
\hline Diabetes mellitus & $96(29.8 \%)$ & 39 (37.1\%) & $55(27 \%)$ & $2(15.4 \%)$ & 0.092 \\
\hline Smoker & $11(3.4 \%)$ & $4(3.8 \%)$ & $6(2.9 \%)$ & $1(7.7 \%)$ & 0.63 \\
\hline Chronic kidney disease & $105(32.6 \%)$ & $31(29.5 \%)$ & $70(34.3 \%)$ & $4(30.8 \%)$ & 0.68 \\
\hline Previous AMl & $72(22.4 \%)$ & $19(18.1 \%)$ & $51(25 \%)$ & $2(15.4 \%)$ & 0.31 \\
\hline Previous $\mathrm{PCl}$ & $69(21.4 \%)$ & $21(20 \%)$ & $45(22.1 \%)$ & $3(23.1 \%)$ & 0.90 \\
\hline Previous CABG & $71(22.0 \%)$ & $20(19 \%)$ & $49(24 \%)$ & $2(15.4 \%)$ & 0.51 \\
\hline CAD & $140(44.3 \%)$ & $50(49 \%)$ & $84(41.8 \%)$ & $6(46.2 \%)$ & 0.49 \\
\hline COPD & $120(37.3 \%)$ & $38(36.2 \%)$ & $78(38.2 \%)$ & $4(30.8 \%)$ & 0.83 \\
\hline Previous pacemaker & $29(9 \%)$ & $8(7.6 \%)$ & $20(9.8 \%)$ & $1(7.7 \%)$ & 0.80 \\
\hline Logistic EuroSCORE & $24.0 \pm 16.9$ & $21.1 \pm 60.8$ & $25.4 \pm 60.5$ & $25.2 \pm 21.4$ & 0.09 \\
\hline STS score & $9.5 \pm 9.3$ & $9.9 \pm 10.1$ & $8.1 \pm 7.8$ & $12.5 \pm 9.3$ & 0.14 \\
\hline NYHA class I or II & $106(33.1 \%)$ & $36(35 \%)$ & 65 (31.9\%) & $5(38.5 \%)$ & 0.79 \\
\hline NYHA class III or IV & $214(66.9 \%)$ & $67(65 \%)$ & $139(68.1 \%)$ & $8(61.5 \%)$ & 0.79 \\
\hline Angina & $98(31 \%)$ & $35(34.3 \%)$ & 59 (29.2\%) & 4 (33.3\%) & 0.65 \\
\hline Syncope & $59(18.5 \%)$ & $24(23.3 \%)$ & $31(15.3 \%)$ & $4(30.8 \%)$ & 0.11 \\
\hline
\end{tabular}

AMI, acute myocardial infarction; CABG, coronary artery bypass graft; CAD, coronary artery disease; COPD, chronic obstructive pulmonary disease; NYHA, New York Heart Association; $\mathrm{PCl}$, percutaneous coronary intervention. 
Table 2 Baseline echocardiographic characteristics according to postprocedural aortic regurgitation grade

\begin{tabular}{|c|c|c|c|c|c|}
\hline & $\begin{array}{c}\text { Overall } \\
(n=322)\end{array}$ & $\begin{array}{l}\text { No aortic } \\
\text { regurgitation }(n=105)\end{array}$ & $\begin{array}{l}\text { Mild aortic } \\
\text { regurgitation }(n=204)\end{array}$ & $\begin{array}{l}\text { Moderate/severe aortic } \\
\text { regurgitation }(n=13)\end{array}$ & $P$-value \\
\hline LVEF & $51.4 \pm 12.7$ & $53 \pm 11.5$ & $50.6 \pm 13.2$ & $49.6 \pm 15$ & 0.25 \\
\hline LVEF $<40 \%$ & $46(14.3 \%)$ & $11(10.5 \%)$ & $31(15.2 \%)$ & $4(30.8 \%)$ & 0.11 \\
\hline Mean aortic gradient $(\mathrm{mmHg})$ & $53.3 \pm 15.0$ & $52.0 \pm 15.6$ & $54.5 \pm 15.3$ & $50.4 \pm 11.3$ & 0.31 \\
\hline Maximum aortic gradient $(\mathrm{mmHg})$ & $86 \pm 22.0$ & $82.4 \pm 19.6$ & $88.3 \pm 24.0$ & $81.5 \pm 17.5$ & 0.07 \\
\hline Anatomic valve area (TEE, AVA $\mathrm{cm}^{2}$ ) & $0.71 \pm 0.22$ & $0.8 \pm 0.22$ & $0.69 \pm 0.21$ & $0.65 \pm 0.13$ & 0.003 \\
\hline \multicolumn{6}{|l|}{ Aortic annulus diameter (mm) } \\
\hline Measured with CT & $22.9 \pm 3.1$ & $23.0 \pm 0.29$ & $23.3 \pm 1.9$ & $24.3 \pm 2.1$ & 0.24 \\
\hline Measured with TEE & $23.1 \pm 4.1$ & $23.5 \pm 1.8$ & $23.4 \pm 2.1$ & $23.9 \pm 2.0$ & 0.80 \\
\hline Measured with TTE & $22.6 \pm 3.0$ & $22.8 \pm 1.5$ & $23.0 \pm 1.8$ & $22.8 \pm 1.4$ & 0.92 \\
\hline Any previous aortic regurgitation & $247(78.2 \%)$ & $72(70.6 \%)$ & $165(82.1 \%)$ & $10(76.9 \%)$ & 0.08 \\
\hline LV end-diastolic diameter (mm) & $52.1 \pm 7.5$ & $50.5 \pm 6.3$ & $52.9 \pm 7.9$ & $56.5 \pm 9.5$ & 0.035 \\
\hline LV end-systolic diameter (mm) & $33.8 \pm 8.1$ & $32.8 \pm 8.5$ & $34.3 \pm 7.6$ & $40.3 \pm 9.0$ & 0.25 \\
\hline Any mitral regurgitation & $268(83.2 \%)$ & $86(81.9 \%)$ & $172(84.3 \%)$ & $10(76.9 \%)$ & 0.71 \\
\hline
\end{tabular}

AVA, aortic valve area; CT, computed tomography; LV, left ventricular; LVEF, left ventricular ejection fraction; TEE, transesophageal echocardiography; TTE, transthoracic echocardiography.

postprocedural aortic regurgitation, $27(13.2 \%)$ in patients with mild postprocedural aortic regurgitation $(P=0.004$ vs. no aortic regurgitation) and $6(46.2 \%)$ in patients with moderate/severe postprocedural aortic regurgitation $(P<0.001$ vs. no or mild postprocedural aortic regurgitation).

\section{Predictors of mortality}

At multivariable analysis, postprocedural aortic regurgitation [hazard ratio $(\mathrm{HR})=2.65$ absent vs. present any grade, 95\% confidence interval $(\mathrm{CI})=1.11-6.29 ; P=0.027)]$, BMI $\quad(\mathrm{HR}=0.878$ for every $1 \mathrm{U}$ increase, $95 \%$ $\mathrm{CI}=0.814-0.947 ; P=0.001)$, STS score $(\mathrm{HR}=1.033$ for every $1 \mathrm{U}$ increase, $95 \% \mathrm{CI}=1.010-1.058 ; P=0.005)$ and $\mathrm{LVEF}(\mathrm{HR}=1.14$ for every $5 \%$ decrease, $96 \% \mathrm{CI}=1.03$ $1.26 ; P=0.015)$ were found to be independent predictors of midterm mortality (Table 6).

\section{Impact of postprocedural aortic regurgitation on midterm mortality}

Kaplan-Meier curves for all-cause and cardiovascular mortality according to postprocedural aortic regurgitation grade are shown in Fig. 2. Actuarial all-cause mortality at 1 year was higher in patients with moderate/severe postprocedural aortic regurgitation than in those with mild (33.3 vs. $13.7 \%$; log-rank $P=0.02)$ and absent postprocedural aortic regurgitation $(9.8 \%$; log-rank $P=0.002)$. Actuarial all-cause mortality, however, was not different in patients with mild and with absent aortic regurgitation (log-rank $P=0.21$ ) (Fig. 2a). Actuarial cardiovascular mortality was significantly higher in patients with moderate/severe aortic regurgitation than in those with absent (33.3 vs. 3.2\%, logrank $P<0.0001)$ and mild aortic regurgitation $(33.4$ vs. $8.4 \%$, log-rank $P=0.002)$. Actuarial cardiovascular mortality was also significantly different in the mild aortic regurgitation group compared with that in the absent aortic regurgitation group (8.4 vs. $3.2 \%, \log$-rank $P=0.03$ ) (Fig. 2b).

\section{Natural history of postprocedural aortic regurgitation}

TTE was performed during follow-up at 30 days, 6 months, 1 year and after 1 year. Complete TTE data were available for 136 patients, which were analyzed in order to assess the natural history of postprocedural aortic regurgitation.

\section{Six months}

Among the 44 (32.3\%) patients without aortic regurgitation at discharge, $34(77.3 \%)$ patients remained free from aortic regurgitation at 6-month follow-up, whereas

Table 3 Procedural characteristics according to postprocedural aortic regurgitation grade

\begin{tabular}{|c|c|c|c|c|c|}
\hline & $\begin{array}{l}\text { Overall } \\
(n=322)\end{array}$ & $\begin{array}{l}\text { No aortic } \\
\text { regurgitation }(n=105)\end{array}$ & $\begin{array}{l}\text { Mild aortic } \\
\text { regurgitation }(n=204)\end{array}$ & $\begin{array}{l}\text { Moderate/severe aortic } \\
\text { regurgitation }(n=13)\end{array}$ & $P$-value \\
\hline \multicolumn{6}{|l|}{ Access } \\
\hline Femoral & $261(81.1 \%)$ & $81(77.1 \%)$ & $169(82.8 \%)$ & $11(84.6)$ & 0.39 \\
\hline Apical & $24(7.4 \%)$ & $11(10.5 \%)$ & $12(5.9 \%)$ & $1(7.7 \%)$ & 0.34 \\
\hline Subclavian & $34(10.6 \%)$ & $11(10.5 \%)$ & $22(10.8 \%)$ & $1(7.7 \%)$ & 0.93 \\
\hline Aortic & $3(0.9 \%)$ & $2(1.9 \%)$ & $1(0.5 \%)$ & $0(0 \%)$ & 0.44 \\
\hline \multicolumn{6}{|c|}{ Transcatheter valve type } \\
\hline CoreValve & $128(39.8 \%)$ & $40(38.1 \%)$ & $84(41.2 \%)$ & $4(30.8 \%)$ & 0.69 \\
\hline $26 \mathrm{~mm}$ & $47(36.7 \%)$ & $16(40 \%)$ & $30(35.7 \%)$ & $1(25 \%)$ & 0.79 \\
\hline $29 \mathrm{~mm}$ & $81(63.3 \%)$ & $24(60 \%)$ & $54(64.3 \%)$ & $3(75 \%)$ & 0.62 \\
\hline Edwards & $194(60.2 \%)$ & $65(61.9 \%)$ & $120(58.8 \%)$ & 9 (69.2\%) & 0.79 \\
\hline $23 \mathrm{~mm}$ & 74 (38.1\%) & $21(32.3 \%)$ & $49(40.8 \%)$ & $4(44.4 \%)$ & 0.48 \\
\hline $26 \mathrm{~mm}$ & $119(61.3 \%)$ & $43(66.2 \%)$ & $71(59.2 \%)$ & $5(55.6 \%)$ & 0.60 \\
\hline $29 \mathrm{~mm}$ & $1(0.5 \%)$ & $1(1.5 \%)$ & $0(0 \%)$ & $0(0 \%)$ & 0.36 \\
\hline
\end{tabular}


Table 4 Causes of overall in-hospital death according to postprocedural aortic regurgitation grade

\begin{tabular}{|c|c|c|c|c|}
\hline In-hospital causes of death & $\begin{array}{c}\text { Overall } \\
{[n=13 / 322(4.0 \%)]}\end{array}$ & $\begin{array}{c}\text { No aortic } \\
\text { regurgitation } \\
{[n=1 / 105(0.9 \%)]}\end{array}$ & $\begin{array}{c}\text { Mild aortic } \\
\text { regurgitation } \\
{[n=7 / 20(3.4 \%)]}\end{array}$ & $\begin{array}{l}\text { Moderate/severe } \\
\text { aortic regurgitation } \\
{[n=5 / 13(38.5 \%)}\end{array}$ \\
\hline Aortic dissection & 3 & 0 & 2 & 1 \\
\hline Cardiogenic shock & 2 & 1 & 0 & 1 \\
\hline Multiorgan failure & 2 & 0 & 1 & 1 \\
\hline Arrhythmia & 2 & 0 & 1 & 1 \\
\hline Aortic annulus rupture & 1 & 0 & 0 & 1 \\
\hline Retroperitoneal bleeding & 1 & 0 & 1 & 0 \\
\hline Right ventricular failure & 1 & 0 & 1 & 0 \\
\hline Interventricular septum rupture & 1 & 0 & 1 & 0 \\
\hline
\end{tabular}

progression to mild aortic regurgitation was seen in 10 $(22.7 \%)$ patients. Of the $88(64.7 \%)$ patients with mild aortic regurgitation at discharge, $75(85.2 \%)$ patients remained stable, whereas aortic regurgitation resolved in $12(13.6 \%)$ patients and progressed to moderate/severe in $1(1.2 \%)$ patient. Of the four $(2.9 \%)$ patients with moderate/severe aortic regurgitation at discharge, two remained stable, whereas aortic regurgitation resolved in one $(25 \%)$ patient and reduced to mild in $1(25 \%)$ patient at 6-month follow-up.

\section{One year}

At 1-year follow-up, 44/47 (93.6\%) patients without aortic regurgitation at 6 months remained stable, whereas progression to mild aortic regurgitation was observed in 3 (6.4\%) patients. Of the 86 patients with mild aortic regurgitation at 6 months, $77(89.5 \%)$ remained stable, whereas in $6(7 \%)$ patients aortic regurgitation resolved and in $3(3.5 \%)$ patients worsened to moderate/severe. Moderate/severe aortic regurgitation remained stable in three patients. After the 1-year follow-up, postprocedural aortic regurgitation worsened in only one patient, from mild to severe, because of infective endocarditis in an Edwards SAPIEN THV (cusp laceration with severe central aortic regurgitation) that required a subsequent second TAVI procedure (valve-in-valve).

\section{Discussion}

The main findings of the present study are as follows:

(1) Postprocedural aortic regurgitation was frequent and occurred in $67.4 \%$ of patients (217). Among these, aortic regurgitation was moderate/severe in only $6 \%$ of patients (13/217).

Fig. 1

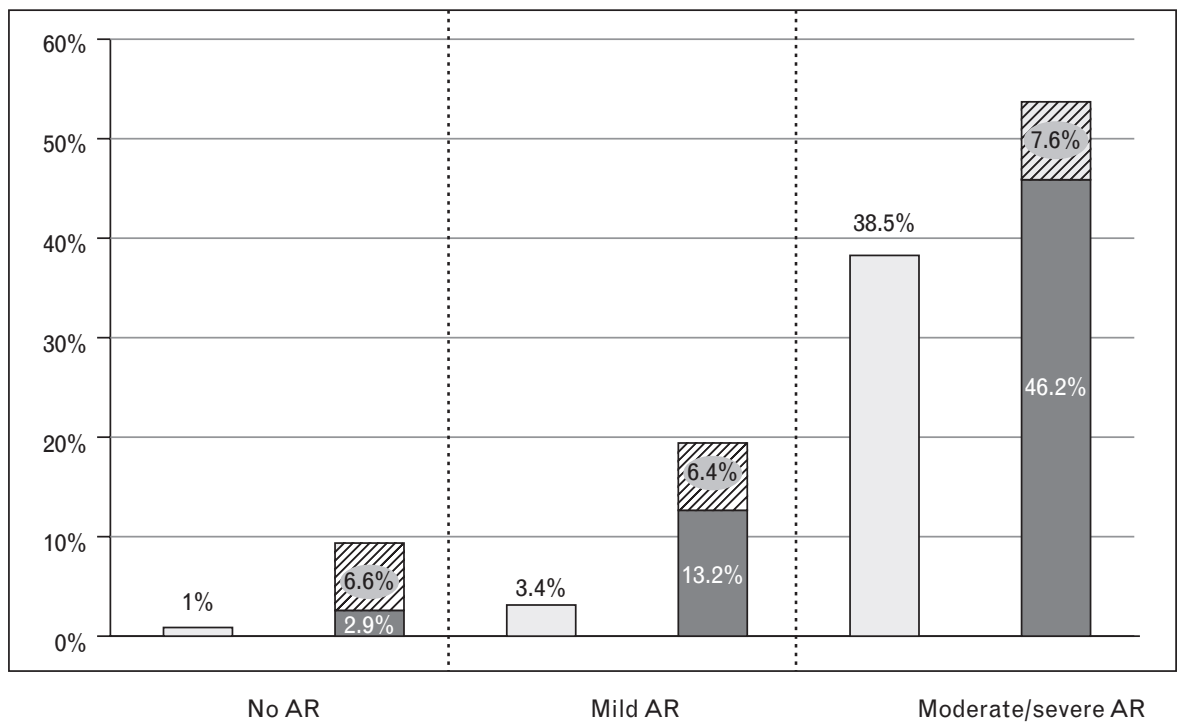

Cardiovascular and all-cause mortality according to postprocedural aortic regurgitation grade. AR, aortic regurgitation. $P$-value for trend $<0.001$. 


\begin{tabular}{|c|c|c|c|c|}
\hline Cause of death & $\begin{array}{c}\text { Overall } \\
{[n=44 / 322(13.6 \%)]}\end{array}$ & $\begin{array}{c}\text { No aortic } \\
\text { regurgitation } \\
{[n=8 / 105(0.7 \%)]}\end{array}$ & $\begin{array}{c}\text { Mild aortic } \\
\text { regurgitation } \\
{[n=33 / 204(16 \%)]}\end{array}$ & $\begin{array}{c}\text { Moderate/severe } \\
\text { aortic regurgitation } \\
{[n=3 / 13(23 \%)]}\end{array}$ \\
\hline \multicolumn{5}{|l|}{ Cardiovascular causes } \\
\hline Ischemic stroke & 3 & 0 & 3 & 0 \\
\hline Hemorrhagic stroke & 2 & 0 & 2 & 0 \\
\hline Malignant arrhythmia & 1 & 0 & 1 & \\
\hline Heart failure & 7 & 0 & 6 & 1 \\
\hline Interventricular septum rupture & 1 & 0 & 1 & \\
\hline Myocardial infarction & 3 & 2 & 0 & 1 \\
\hline Sudden death & 8 & 0 & 8 & 0 \\
\hline \multicolumn{5}{|l|}{ Noncardiovascular causes } \\
\hline Multiorgan failure & 3 & 2 & 1 & 0 \\
\hline Sepsis & 4 & 1 & 2 & 1 \\
\hline Hepatorenal syndrome & 1 & 0 & 1 & 0 \\
\hline Cancer & 3 & 1 & 2 & 0 \\
\hline Subdural hematoma & 1 & 0 & 1 & 0 \\
\hline Hepatic cirrhosis & 2 & 0 & 2 & 0 \\
\hline Respiratory failure & 3 & 1 & 2 & 0 \\
\hline Femoral fracture & 1 & 0 & 1 & 0 \\
\hline Renal failure & 1 & 1 & 0 & 0 \\
\hline
\end{tabular}

(2) Although uncommon, moderate/severe aortic regurgitation is associated with a significant impact on early and midterm mortality.

(3) Even mild aortic regurgitation appears to be associated with increased cardiovascular mortality.

(4) The severity of postprocedural aortic regurgitation appears to remain stable during follow-up in the majority of patients, irrespective of the THV implanted.

Variable rates of postprocedural aortic regurgitation following TAVI have been reported in the literature. Depending on the method of assessment (angiography vs. echocardiography, quantitative vs. semiquantitative), the reported incidence of postprocedural aortic regurgitation varies between 40 and $67 \%$ for trivial to mild aortic regurgitation ${ }^{22-24}$ and 7 and $20 \%$ for moderate-to-severe aortic regurgitation. ${ }^{2-25}$ According to the VARC definition of aortic regurgitation, we reported a $67.4 \%$ incidence of total postprocedural aortic regurgitation (of which $94 \%$ was mild and $6 \%$ moderate/severe), in agreement with the results from other studies. ${ }^{6,15,26-29}$ On the other hand, we reported a $6 \%$ incidence of moderate/ severe postprocedural aortic regurgitation, which is lower than the $4-17.2 \%$ incidence demonstrated by other studies. ${ }^{6,15,26-29}$ This may reflect differences in the

Table 6 Predictors of midterm mortality at multivariable Cox regression analysis

\begin{tabular}{|c|c|c|c|c|}
\hline \multirow[b]{2}{*}{ Variables } & \multirow{2}{*}{$\begin{array}{l}\text { Univariate } \\
\quad P\end{array}$} & \multicolumn{3}{|c|}{ Multivariate } \\
\hline & & $P$ & HR & $95 \% \mathrm{Cl}$ \\
\hline BMI (for every $1 \mathrm{U}$ increase) & 0.001 & 0.001 & 0.87 & $0.81-0.94$ \\
\hline STS score (for every $1 \mathrm{U}$ increase) & 0.001 & 0.005 & 1.03 & $1.01-1.05$ \\
\hline LVEF (for every $5 \%$ decrease) & 0.001 & 0.015 & 1.14 & $1.03-1.26$ \\
\hline $\begin{array}{l}\text { Postprocedural aortic regurgitation } \\
\text { (absent vs. present any grade) }\end{array}$ & 0.027 & 0.027 & 2.65 & $1.11-6.29$ \\
\hline
\end{tabular}

$\mathrm{Cl}$, confidence interval; $\mathrm{HR}$, heart rate; LVEF, left ventricle ejection fraction. definitions of aortic regurgitation applied (VARC vs. non-VARC), the interventional technique used at each institution and differences in the timing and method used to assess postprocedural aortic regurgitation. Recent data from large studies ${ }^{3,29}$ identified significant postprocedural aortic regurgitation (moderate/severe) as a predictor of early and midterm mortality. This was also the case in our study as this was associated with a worse outcome in terms of survival free from overall and cardiovascular mortality as compared with absent or mild postprocedural aortic regurgitation. Aside from the clear influence of moderate/severe postprocedural aortic regurgitation on mortality, the impact of mild aortic regurgitation on midterm outcome has yielded conflicting results in recent literature. ${ }^{4,30}$ Such discrepancies may be related to the challenges associated with both the echocardiographic and angiographic identification and quantification of postprocedural aortic regurgitation, which still remains controversial and imprecise. ${ }^{31}$

In our study, even mild aortic regurgitation had a significant impact on midterm outcome as it was associated with a higher cardiovascular mortality at follow-up as compared with no aortic regurgitation. Previous TTE-based studies ${ }^{32}$ have suggested that even mild postprocedural aortic regurgitation may be clinically detrimental, a finding that is difficult to explain physiologically. The reason as to why mild postprocedural aortic regurgitation may influence cardiovascular mortality remains unclear. A possible explanation is that a hypertrophic left ventricle that has been exposed to midterm pressure overload may not be able to adapt abruptly to volume overload, even if mild, especially if preprocedural aortic regurgitation had not been present. Furthermore, recent studies $^{33,34}$ showed that aortic regurgitation severity is underestimated by TTE compared with cardiac MRI, so one may speculate that at least part of these patients with aortic regurgitation classified as mild may have had at 


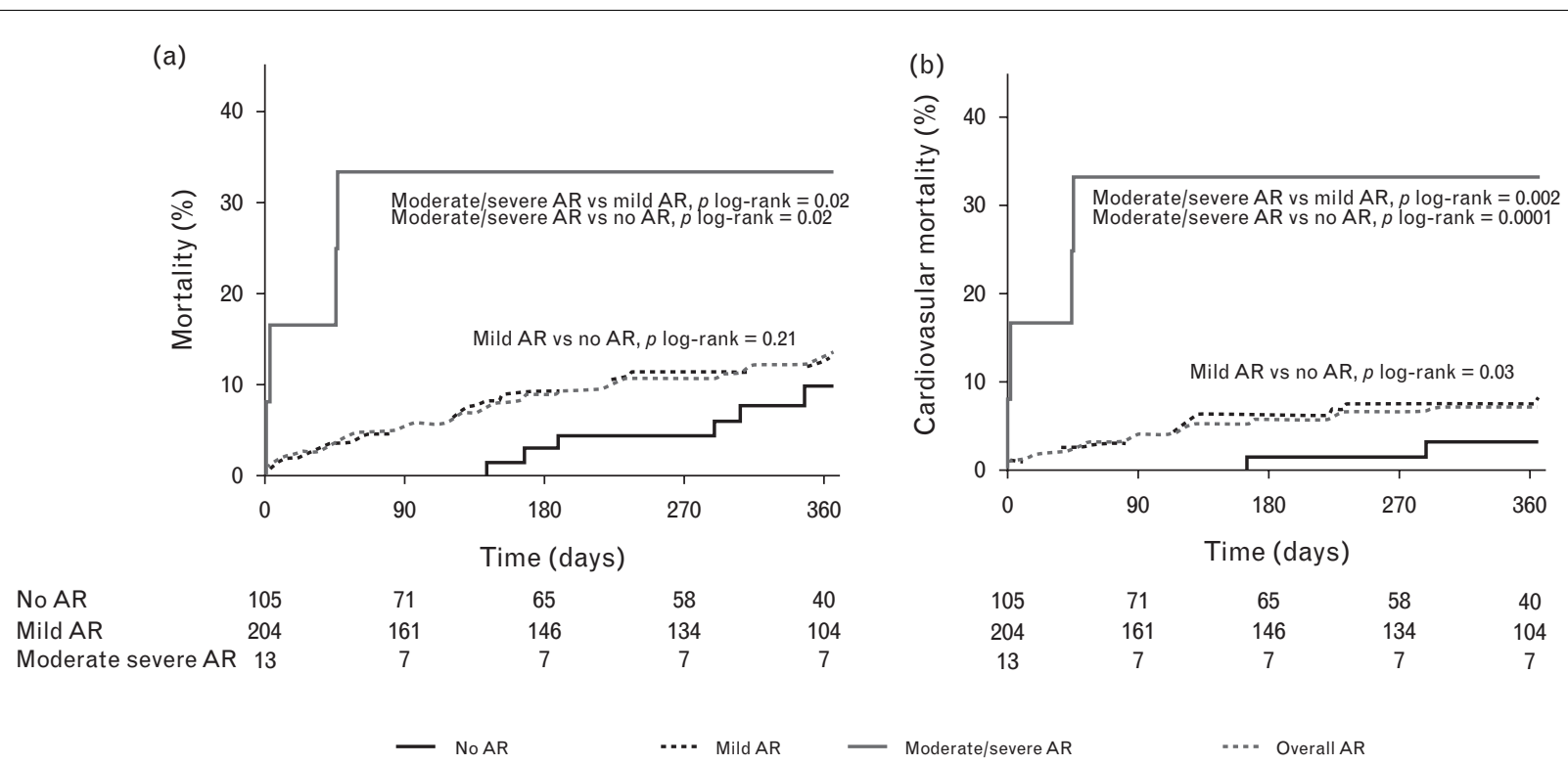

Kaplan-Meier curves for all-cause (a) and cardiovascular mortality (b) according to postprocedural aortic regurgitation grade (event rates and $P$ values presented here were calculated by the Kaplan-Meier method and compared with the log-rank test and differ from those in the results that were calculated as categorical variables and compared with the chi-square test).

least moderate aortic regurgitation. This finding could help to explain the worse clinical outcome of these patients with 'mild' aortic regurgitation. Therefore, the potential incremental prognostic value of cardiac MRI should be prospectively investigated in this setting. Following an accurate assessment, the complete elimination of a postprocedural aortic regurgitation represents another important goal in THV implantation procedures. Mismatch of valve annulus and prosthesis diameter size, aortic root calcification and suboptimal device implantation have already been identified as major culprits for postprocedural aortic regurgitation in a recent metaanalysis. ${ }^{35}$ Undersizing of the THV to the annulus size is a key reason for postprocedural aortic regurgitation. Thus, precise annulus sizing and quantification of the extent and location of calcification in the aortic root by appropriate preprocedural 3D imaging are of great importance in order to adequately size the THV and prevent postprocedural aortic regurgitation. ${ }^{36-38}$ Along with the preprocedural planning, postimplantation countermeasures such as valve-in-valve implantation, valve snaring and postdilatation may also be considered to reduce moderate/severe postprocedural aortic regurgitation (particularly after CoreValve implantation). On the basis of the prognostic importance of mild aortic regurgitation shown in our study, we believe that it would be reasonable to consider postdilatation in selected patients with mild aortic regurgitation in whom clear valve underexpansion is evident but should be avoided in patients with severe asymmetrical calcification or left ventricular outflow tract calcification. Although all these periprocedural measures are certainly important in reducing aortic regurgitation with standard devices, the preliminary data from new-generation THVs (with improved subannular fixation designs or external space-filling materials) are promising and suggest that residual postprocedural aortic regurgitation may become an irrelevant issue in the near future. ${ }^{39,40}$

\section{Natural history of postprocedural aortic regurgitation}

To date, limited information is available regarding the natural history of postprocedural aortic regurgitation. Among the 136 patients with complete echocardiographic follow-up data, aortic regurgitation appeared to remain stable from discharge to follow-up in the majority of patients irrespective of the THV implanted. Our data suggest that if change in aortic regurgitation does occur, whether it is improvement or deterioration, this usually tends to happen within the first 6 months. It appears that from 6 months to 1 year, significant change in the degree of aortic regurgitation is uncommon. This finding is consistent with the 3-year data of the Placement of aortic transcatheter valves trial ${ }^{32}$ demonstrating no significant change in aortic regurgitation during follow-up among the patients who underwent echocardiographic evaluation after TAVI. Our data, however, are in contradiction to the CoreValve U.S. Pivotal Trial in which $80 \%$ of patients with moderate postprocedural aortic regurgitation at 1 month who survived to 1 year experienced a reduction in the aortic regurgitation over time. ${ }^{41}$ The reason for this may be related to the fact that both balloon-expandable and self-expanding valves were implanted in our study 


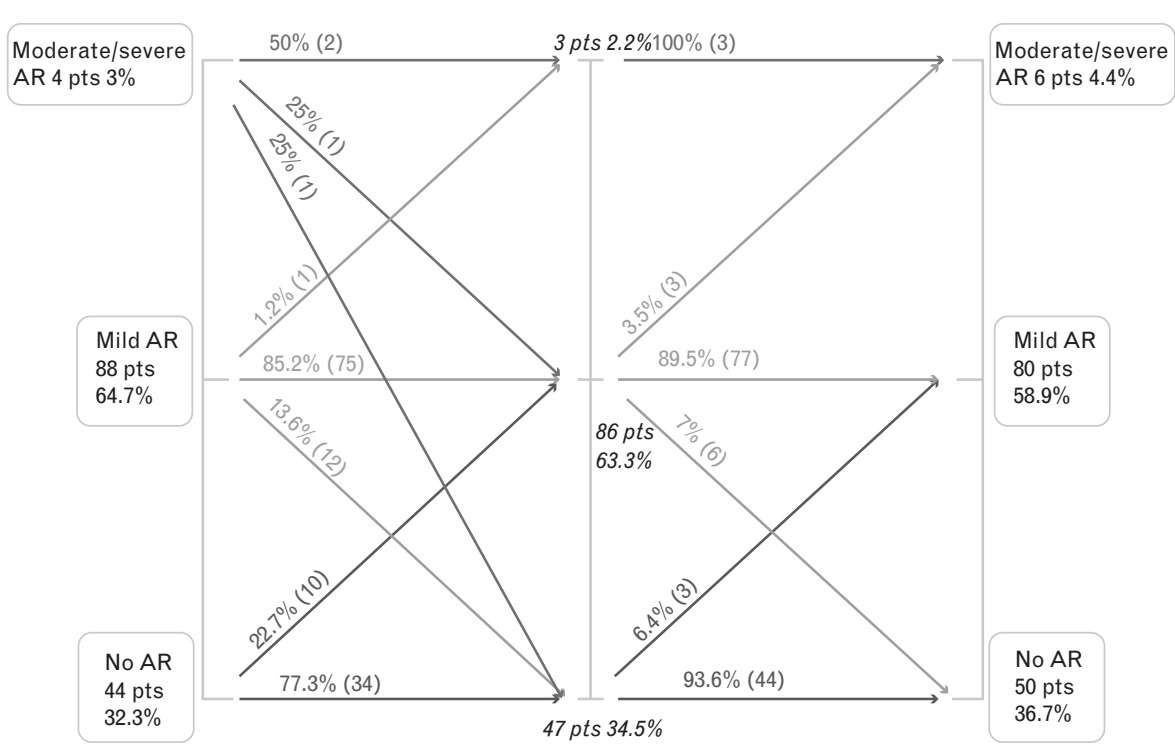

Echocardiographic evolution of postprocedural aortic regurgitation at follow-up.

and the high rate of postdilatation in CoreValve may have negated this late effect. Echocardiographic evolution of postprocedural aortic regurgitation at follow-up is shown in Fig. 3.

\section{Predictors of mortality}

In previously published studies, ${ }^{13}$ significant post-TAVI aortic regurgitation was identified as one of the predictors of midterm mortality. Our results demonstrate similar findings. On multivariable analysis, BMI, STS score and LVEF were also identified as predictors of midterm mortality. Given the advanced age of patients undergoing TAVI, low BMI could represent a marker of cachexia and thus an index of frailty. These patients may tolerate poorly the potential complications associated with the procedure. The type of bioprosthesis used for TAVI was not identified as a predictor of midterm mortality consistently with the results of a recent randomized trial ${ }^{42}$ that compared the self-expandable THV with the balloon-expandable THV.

\section{Study limitations}

The present study reports a retrospective single-center TAVI cohort of limited size and follow-up period. The echocardiographic assessment of aortic regurgitation severity may be operator dependent, and hence it might have been more accurate to have a single operator or core lab evaluate aortic regurgitation (postprocedure and during follow-up) in order to maintain uniformity. Aortic regurgitation assessment, however, was performed as per guidelines and by an independent experienced echocardiographist. The mixed cohort of THV included in the present analysis, although it may be perceived as a limitation, reflects our everyday clinical practice.

\section{Conclusion}

Postprocedural aortic regurgitation is a frequent event and has an adverse effect on early and midterm mortality. This impact is higher with increasing grades of aortic regurgitation, but it is present even in the case of mild postprocedural aortic regurgitation compared with absent. The present study confirms that every effort (i.e. postdilatation, snaring, valve-in-valve implantation) should be made to minimize the grade of postprocedural aortic regurgitation with current devices through comprehensive preprocedural planning and meticulous procedural execution. New-generation THVs are needed to address the issues of repositionability in order to facilitate accurate placement and include additional features to minimize postprocedural aortic regurgitation, which should further improve TAVI outcomes.

\section{Acknowledgements}

All the authors take responsibility for all aspects of the reliability and freedom from bias of the data presented and their discussed interpretation.

There are no potential conflicts of interest or funding sources to disclose.

\section{References}

1 Cribier A, Eltchaninoff H, Bash A, Borenstein N, Tron C, Bauer F, et al. Percutaneous transcatheter implantation of an aortic valve prosthesis for calcific aortic stenosis: first human case description. Circulation 2002; 106:3006-3008. 
2 Vahanian A, Alfieri O, Al-Attar N, Antunes M, Bax J, Cormier B, et al. Transcatheter valve implantation for patients with aortic stenosis: a position statement from the European Association of Cardio-Thoracic Surgery (EACTS) and the European Society of Cardiology (ESC), in collaboration with the European Association of Percutaneous Cardiovascular Interventions (EAPCI). Eur Heart J 2008; 29:1463-1470.

3 Tamburino C, Capodanno D, Ramondo A, Petronio AS, Ettori F, Santoro G et al. Incidence and predictors of early and late mortality after transcatheter aortic valve implantation in 663 patients with severe aortic stenosis. Circulation 2011; 123:299-308.

4 Kodali SK, Williams MR, Smith CR, Svensson LG, Webb JG, Makkar RR, et al. Two-year outcomes after transcatheter or surgical aortic-valve replacement. N Engl J Med 2012; 366:1686-1695.

5 Sannino A, Losi MA, Schiattarella GG, Gargiulo G, Perrino C, Stabile E, et al. Meta-analysis of mortality outcomes and mitral regurgitation evolution in 4,839 patients having transcatheter aortic valve implantation for severe aortic stenosis. Am J Cardiol 2014; 114:875-882.

6 Detaint D, Lepage L, Himbert D, Brochet E, Messika-Zeitoun D, lung B, et al. Determinants of significant paravalvular regurgitation after transcatheter aortic valve: implantation impact of device and annulus discongruence. JACC Cardiovasc Interv 2009; 2:821-827.

7 Jabbour A, Ismail TF, Moat N, Gulati A, Roussin I, Alpendurada F, et al. Multimodality imaging in transcatheter aortic valve implantation and postprocedural aortic regurgitation: comparison among cardiovascular magnetic resonance, cardiac computed tomography, and echocardiography. J Am Coll Cardiol 2011; 58:2165-2173.

8 Schultz CJ, Weustink A, Piazza N, Otten A, Mollet N, Krestin G, et al. Geometry and degree of apposition of the CoreValve ReValving system with multislice computed tomography after implantation in patients with aortic stenosis. J Am Coll Cardiol 2009; 54:911-918.

9 Delgado V, Ng AC, van de Veire NR, van der Kley F, Schuijf JD, Tops LF et al. Transcatheter aortic valve implantation: role of multidetector row computed tomography to evaluate prosthesis positioning and deployment in relation to valve function. Eur Heart $J 2010 ; 31: 1114-1123$.

10 Ewe SH, Ng AC, Schuijf JD, van der Kley F, Colli A, Palmen M, et al. Location and severity of aortic valve calcium and implications for aortic regurgitation after transcatheter aortic valve implantation. Am J Cardiol 2011; 108:1470-1477.

11 Takagi K, Latib A, Al-Lamee R, Mussardo M, Montorfano M, Maisano F, et al. Predictors of moderate-to-severe paravalvular aortic regurgitation immediately after CoreValve implantation and the impact of postdilatation. Catheter Cardiovasc Interv 2011; 78:432-443.

12 Munoz-Garcia AJ, Alonso-Briales JH, Jimenez-Navarro MF, CaballeroBorrego J, Dominguez-Franco AJ, Rodriguez-Bailon I, et al. Mechanisms, treatment and course of paravalvular aortic regurgitation after percutaneous implantation of the CoreValve aortic prosthesis. Int J Cardiol 2011; 149:389-392.

13 Ussia GP, Barbanti M, Imme S, Scarabelli M, Mule M, Cammalleri V, et al. Management of implant failure during transcatheter aortic valve implantation. Catheter Cardiovasc Interv 2010; 76:440-449.

14 Grube E, Buellesfeld L, Mueller R, Sauren B, Zickmann B, Nair D, et al. Progress and current status of percutaneous aortic valve replacement: results of three device generations of the CoreValve Revalving system. Circ Cardiovasc Interv 2008; 1:167-175.

15 Webb JG, Altwegg L, Boone RH, Cheung A, Ye J, Lichtenstein S, et al. Transcatheter aortic valve implantation: impact on clinical and valve-related outcomes. Circulation 2009; 119:3009-3016.

16 Sherif MA, Abdel-Wahab M, Stocker B, Geist V, Richardt D, Tolg R, et al. Anatomic and procedural predictors of paravalvular aortic regurgitation after implantation of the Medtronic CoreValve bioprosthesis. J Am Coll Cardiol 2010; 56:1623-1629.

17 Godino C, Maisano F, Montorfano M, Latib A, Chieffo A, Michev I, et al. Outcomes after transcatheter aortic valve implantation with both EdwardsSAPIEN and CoreValve devices in a single center: the Milan experience. JACC Cardiovasc Interv 2010; 3:1110-1121.

18 Vahanian A, Baumgartner H, Bax J, Butchart E, Dion R, Filippatos G, et al. Guidelines on the management of valvular heart disease: the Task Force on the Management of Valvular Heart Disease of the European Society of Cardiology. Eur Heart J 2007; 28:230-268.

19 Bonow RO, Carabello BA, Chatterjee K, et al. 2008 focused update incorporated into the ACC/AHA 2006 guidelines for the management of patients with valvular heart disease: a report of the American College of Cardiology/American Heart Association Task Force on Practice Guidelines (Writing Committee to Revise the 1998 Guidelines for the Management of Patients With Valvular Heart Disease): endorsed by the Society of Cardiovascular Anesthesiologists, Society for Cardiovascular Angiography and Interventions, and Society of Thoracic Surgeons. Circulation 2008; 118:e523-e661
20 Zamorano JL, Badano LP, Bruce C, Chan KL, Goncalves A, Hahn RT, et al. EAE/ASE recommendations for the use of echocardiography in new transcatheter interventions for valvular heart disease. Eur Heart $J$ 2011; 32:2189-2214.

21 Leon MB, Piazza N, Nikolsky E, Blackstone EH, Cutlip DE, Kappetein AP et al. Standardized endpoint definitions for transcatheter aortic valve implantation clinical trials: a consensus report from the Valve Academic Research Consortium. J Am Coll Cardiol 2011; 57:253-269.

22 Webb JG, Pasupati S, Humphries K, Thompson C, Altwegg L, Moss R, et al. Percutaneous transarterial aortic valve replacement in selected high-risk patients with aortic stenosis. Circulation 2007; 116:755763.

23 Walther T, Simon P, Dewey T, Wimmer-Greinecker G, Falk V, Kasimir MT, et al. Transapical minimally invasive aortic valve implantation: multicenter experience. Circulation 2007; 116:I240-I245.

24 De Jaegere PP, Piazza N, Galema TW, Otten A, Soliman OI, Van Dalen BM, et al. Early echocardiographic evaluation following percutaneous implantation with the self-expanding CoreValve Revalving system aortic valve bioprosthesis. Eurolntervention 2008; 4:351-357.

25 Rodes-Cabau J, Webb JG, Cheung A, Ye J, Dumont E, Feindel CM, et al. Transcatheter aortic valve implantation for the treatment of severe symptomatic aortic stenosis in patients at very high or prohibitive surgical risk: acute and late outcomes of the multicenter Canadian experience. J Am Coll Cardiol 2010; 55:1080-1090.

26 Thomas M, Schymik G, Walther T, Himbert D, Lefevre T, Treede H, et al. Thirty-day results of the SAPIEN Aortic Bioprosthesis European Outcome (SOURCE) registry: a European registry of transcatheter aortic valve implantation using the Edwards SAPIEN valve. Circulation 2010; 122:6269.

27 Jilaihawi H, Chin D, Spyt T, Jeilan M, Vasa-Nicotera M, Bence J, et al. Prosthesis-patient mismatch after transcatheter aortic valve implantation with the Medtronic-Corevalve bioprosthesis. Eur Heart J 2011; 31:857864.

28 Moss RR, Ivens E, Pasupati S, Humphries K, Thompson CR, Munt B, et al. Role of echocardiography in percutaneous aortic valve implantation. JACC Cardiovasc Imaging 2008; 1:15-24.

29 Abdel-Wahab M, Zahn R, Horack M, Gerckens U, Schuler G, Sievert H, et al. Aortic regurgitation after transcatheter aortic valve implantation: incidence and early outcome. Results from the German transcatheter aortic valve interventions registry. Heart 2011; 97:899-906.

30 Van Belle E, Juthier F, Susen S, Vincentelli A, lung B, Dallongeville J, et al. Postprocedural aortic regurgitation in balloon-expandable and selfexpandable transcatheter aortic valve replacement procedures: analysis of predictors and impact on long-term mortality: insights from the FRANCE2 Registry. Circulation 2014; 129:1415-1427.

31 Tarantini G, Gasparetto V, Napodano M, Fraccaro C, Gerosa G, Isabella G. Valvular leak after transcatheter aortic valve implantation: a clinician update on epidemiology, pathophysiology and clinical implications. $A m \mathrm{~J}$ Cardiovasc Dis 2011; 1:312-320.

32 Thourani VH. Three-year results from the PARTNER cohort. Presented at: American College of Cardiology Congress; 8-11th March 2013; San Francisco.

33 Orwat S, Diller GP, Kaleschke G, Kerckhoff G, Kempny A, Radke RM, et al. Aortic regurgitation severity after transcatheter aortic valve implantation is underestimated by echocardiography compared with MRI. Heart 2014; 100:1933-1938.

34 Ribeiro HB, Le Ven F, Larose E, Dahou A, Nombela-Franco L, Urena M, et al. Cardiac magnetic resonance versus transthoracic echocardiography for the assessment and quantification of aortic regurgitation in patients undergoing transcatheter aortic valve implantation. Heart 2014; 100:1924-1932.

35 Athappan G, Patvardhan E, Tuzcu EM, Svensson LG, Lemos PA, Fraccaro $\mathrm{C}$, et al. Incidence, predictors and outcomes of aortic regurgitation after transcatheter aortic valve replacement: meta-analysis and systematic review of literature. J Am Coll Cardiol 2013; 61:1585-1595.

36 Bloomfield GS, Gillam LD, Hahn RT, Kapadia S, Leipsic J, Lerakis S, et al. A practical guide to multimodality imaging of transcatheter aortic valve replacement. JACC Cardiovasc Imaging 2012; 5:441-455

37 Willson AB, Webb JG, Freeman M, Wood DA, Gurvitch R, Thompson CR, et al. Computed tomography-based sizing recommendations for transcatheter aortic valve replacement with balloon-expandable valves: comparison with transesophageal echocardiography and rationale for implementation in a prospective trial. $J$ Cardiovasc Comput Tomogr 2012; 6:406-414.

38 Buzzatti N, Maisano F, Latib A, Cioni M, Taramasso M, Mussardo M, et al. Computed tomography-based evaluation of aortic annulus, prosthesis size and impact on early residual aortic regurgitation after transcatheter aortic valve implantation. Eur J Cardiothorac Surg 2012; 43:43-51. 
39 Schofer J, Colombo A, Klugmann S, Fajadet J, DeMarco F, Tchetche D, et al. Prospective multicenter evaluation of the direct flow medical transcatheter aortic valve. J Am Coll Cardiol 2014; 63:763-768.

40 Meredith I, Walters D, Dumonteil N, Worthley S, Tchetche D, Manohoran $\mathrm{G}$, et al. Transcatheter aortic valve replacement for severe symptomatic aortic stenosis using a repositionable valve system: 30-day primary endpoint results from the REPRISE II study. J Am Coll Cardiol 2014; 64:1339-1348.
41 Adams DH, Popma JJ, Reardon MJ, Yakubov SJ, Coselli JS, Deeb GM, et al. Transcatheter aortic-valve replacement with a self-expanding prosthesis. N Engl J Med 2014; 370:1790-1798.

42 Abdel-Wahab M, Mehilli J, Frerker C, Neumann FJ, Kurz T, Tolg R, et al. Comparison of balloon-expandable vs self-expandable valves in patients undergoing transcatheter aortic valve replacement: the CHOICE randomized clinical trial. JAMA 2014; 311:15031514. 